\title{
Determination of a Cut-Off Point of a Scale for Achievement Motive in Geriatrics That Predicts the Frequency of Undertaking Instrumental Activities of Daily Living in Community-Dwelling Elderly People
}

\author{
Nobuyuki Sano, Hisato Nakazono \\ Department of Occupational Therapy, Fukuoka International University of Health and Welfare, Fukuoka, Japan \\ Email: sanokichi09094@gmail.com
}

How to cite this paper: Sano, N. and Nakazono, H. (2019) Determination of a Cut-Off Point of a Scale for Achievement Motive in Geriatrics That Predicts the Frequency of Undertaking Instrumental Activities of Daily Living in CommunityDwelling Elderly People. Advances in Aging Research, 8, 107-118.

https://doi.org/10.4236/aar.2019.86008

Received: September 10, 2019

Accepted: October 12, 2019

Published: October 15, 2019

Copyright $\odot 2019$ by author(s) and Scientific Research Publishing Inc. This work is licensed under the Creative Commons Attribution-NonCommercial International License (CC BY-NC 4.0). http://creativecommons.org/licenses/by-nc/4.0/

\begin{abstract}
Background: Among elderly people, rehabilitation is important for reducing the risk of falls and hospitalization and to maintain an independent life for longer. Motivation is a factor for elderly people to lead an active daily life and leave home more frequently. Purpose: The purposes of this study were to determine the optimal cut-off point in the Scale for Achievement Motive in Geriatrics (SAMG) that could identify individuals as inactive or active, based on the Frenchay Activities Index (FAI), and to compare characteristics between active and inactive groups classified by the cut-off point. Methods: A cross-sectional study of 285 community-dwelling elderly people measured SAMG and FAI and physical function. Receiver operating characteristic (ROC) analysis was used to calculate the area under the curve (AUC) that was the optimal cut-off point for the SAMG total score, with the associated sensitivity and 1-specificity when compared with the FAI results. Demographic parameters and physical function were compared between two groups defined by cut-off point. Results: The AUC was 0.78 , the optimal cut-off for SAMG total score for indicating inactivity was $\leq 48$, the sensitivity was $77.98 \%$ and the 1 -specificity was $75.00 \%$. The group with SAMG score $>48$ was characterized by a significantly higher proportion of women, fewer people sharing a house, and participation in more hobbies. Discussion: A cut-off point of 48 in the SAMG could be a predictive index of motivation toward goals for individuals with inactive daily activities. The group with score higher than the cut-off was characterized by more women, fewer people living together, and more hobbies than the group with lower scores.
\end{abstract}




\section{Keywords}

Achievement Motive, Instrumental Activities of Daily Living, Cut-Off Point, Preventive Care, Community-Dwelling Elderly People

\section{Introduction}

Aging is progressing rapidly in developed countries, and increasing healthy life expectancy, the age to which an individual remains independent without requiring nursing care, is an important issue [1] [2]. According to the World Health Organization, rehabilitation for elderly people is important for reducing the risk of falls and hospitalization and for maintaining an independent life for longer [3]. An approach to improving the level of activities and participation of older people is to use the framework of the International Classification of Functioning, Disability and Health: this is required in preventive care measures for elderly people in Japan [4]. To promote greater activity, it is recommended that efforts are taken to increase the motivation of elderly people and that suitable places for this are created in the areas where they live [5]. In Japan, there has been an increase in the number of community-based regional salons for elderly people, managed by local residents and volunteers, which offer a location and activities for making friends [6]. These regional salons allow easy participation by elderly people living in the community, regardless of the level of their requirement for nursing care provided by long-term care insurance, and they play a role in preventive care. On the other hand, it has been reported that the elderly people who tend to voluntarily shut themselves away at home decreased activity levels and motivation, and increased the mortality rate [7] [8] [9].

A high level of activity is required to prevent muscle mass reduction and the development of frailty in elderly people [10] [11]. This can be assessed using the Frenchay Activities Index (FAI), which provides an effective evaluation method that captures an individual's status of activities and participation. The FAI was originally developed to assess the status of instrumental activities of daily living (IADL) for stroke patients [12], and many studies have been conducted with patients with various illnesses and injuries, including lower limb amputation [13], multiple sclerosis [14], and spinal cord injury [15], and it has also been applied to the general elderly population [16]. The validity and reliability of various country-specific translations of the scales have been confirmed, including, for the Japanese, Chinese, and Korean versions [17] [18] [19]. Several studies on factor analysis of FAI have been reported. The Japanese version comprises two factors: "domestic chores" and "work and leisure" [17]. It has been shown that women are strongly related to the "domestic chores" factor whereas men are strongly related to the factor of "work and leisure".

Motivation is also a factor in elderly people leading an active daily life and increasing social participation [20] [21] [22]. Individual rehabilitation services set 
rehabilitation goals that are shared between the clients receiving support and their family members, with the therapist providing services based on the client's current and future needs [23] [24]. An individual's intention to achieve a goal is referred to as "achievement motive". This was first defined by Murray as the capacity "to overcome obstacles, to exercise power, to strive to do something difficult as well and as quickly as possible" [25]. The Scale for Achievement Motive in Rehabilitation (SAMR) has been developed as self-reported questionnaire with 10 items that can easily evaluate the achievement motive of clients undergoing individual rehabilitation [22] [26]. So, that this can also be applied to preventive rehabilitation, the 10 items of SAMR that can be answered by those who have not received rehabilitation services have been reorganized to develop the Scale for Achievement Motive in Geriatrics (SAMG) [27] [28]. It is intended that SAMG can be used as a screening test for predicting the amount of daily activity undertaken by elderly people during early preventive rehabilitation interventions. The validity and reliability of the scale development of SAMG have been confirmed, but data to enable the tool to be used to screen the status of IADL of elderly people and the characteristics of the basic attributes and physical function of this population remain to be clarified.

The aims of this study were to determine the optimal cut-off point of SAMG that best differentiated between inactive and active individuals, and to examine whether characteristics differed the two groups classified according to this cut-off point.

\section{Methods}

\subsection{Ethics Statement}

This cross-sectional study was conducted in accordance with the principles of the Declaration of Helsinki and was approved by the Ethics Committee of Kibi International University (No. 17-22). The participants had the right to withdraw from the study at any time for any reason. They indicated their informed consent by completing the questionnaires and handing them to the research staff. This study was supported by JSPS KAKENHI Grant Number JP17H07288.

\subsection{The Inclusion Criteria for Participation}

The participants were community-dwelling people aged $\geq 65$ years who belonged to a regional salon group in Okayama, Japan, recruited by flyers about a health excise program. Fourteen regional salon groups cooperated with this study. Individuals were excluded from participants if they had a mental disorder such as schizophrenia or dementia, they demonstrated a clear decline in cognitive function, or they were unable to read and complete on the questionnaire.

\subsection{Data Collection and Measurements}

Each participant completed the self-assessment questionnaires and then measurements of physical functions. In addition, the research staffs were attached to 
assist and read out the question items as appropriate. The questionnaires were corrected immediately after the data collection to confirm there were no blank items or duplicate responses. Measurements of physical functions were immediately stopped if the participant complained of a physical problem.

\section{1) Questionnaires \\ Demographic parameters}

The demographic parameters collected included age, sex, number of people who shared the participant's house (here referred to as housemates), the number of hobbies the participant participated in, falling history and hospitalization history within the previous three months, and nursing care level according to the participant's long-term care insurance, scored as needing care (1 - 5), needing support $(1-2)$, or none $(0)$. The number of housemates and hobbies were determined by asking the following: "How many people are living together in your current residence?" and "How many hobbies and practices do you do regularly at least once a week?" Falling and hospitalization history was determined by asking if the participant had experienced one or more falls or hospitalization during the previous three months (yes $=1$, no $=0$ ).

\section{Scale for achievement motive in geriatrics}

SAMG was used to evaluate each participant's achievement motive, based on SAMR [27] [28]. SAMG is structured according to two types of factor: those derived from self-mastery (e.g., "I think that I can overcome any difficulties to achieve something important to myself.") and those that are means/process-oriented (e.g., "I want to choose a way of life that I can fully satisfy"). Each of the 10 SAMG item is scored using a 7-point Likert scale, ranging from 1 (strongly disagree) to 7 (strongly agree). The total SAMG scores was therefore in the range (10 - 70), with higher scores representing greater achievement motive.

\section{Frenchay activities index}

The FAI was used to evaluate how frequently the participants undertook IADLs [12] [17]. This was evaluated based on the condition of the participants in the last month. Each item of the 15 FAI items is scored using a 4-point Likert scale, ranging from 0 (never or none) to 3 (most days, at least once per week, etc.). The total FAI scores was therefore in the range $(0-45)$, with higher scores representing greater activity and movement. A total score $<15$ points is interpreted as indicating the respondent is inactive [29].

\section{2) Physical function}

Physical functions measured were grip strength, gait speed, and muscle strength of the knee extensor.

Grip strength has been reported to be an indicator of the muscular strength status of the whole body, and it has been shown to be associated frailty falls and mortality in the elderly [30]. Grip strength was measured twice for each hand using an analog Smedley dynamometer in the standing or sitting position with shoulder adduction and neutral rotation and full extension of the elbow [31]. The results were recorded as the mean of two trials in the stronger hand.

Gait speed has been shown to be closely associated with the expansion of liv- 
ing range, IADL performance, and the frequency of leaving the house, and it is considered to be an index that reflects the amount of daily activity [32]. The participant was instructed to walk as fast as was safety possible and was allowed to use an assistive device such as a T-cane [33]. To minimize the effects of acceleration and deceleration the participant's gait speed was measured over the middle $5 \mathrm{~m}$ of an 11-m walkway (timed with a stopwatch).

The Muscle strength of the knee extensor has been reported to be an index of lower limb strength, and can be understood from objective indicators of the relationship with walking speed and the amount of daily activity performed [34]. The muscle strength of the knee extensor was measured twice with a hand-held dynamometer ( $\mu$ Tas F-1; ANIMA Co., Tokyo, Japan) in the sitting position with 90-degree flexion of the hip and knee joints [35]. This measurement $(\mathrm{N})$ was calculated by dividing the length (in $\mathrm{cm}$ ) of the lower limb (from the great trochanter of the femur to the lateral malleolus) by the participant's self-reported body weight (in kgf).

\subsection{Statistical Methods}

The demographic parameters, score on the scales, and physical function indices are summarized as mean and standard deviation (SD) or the median value.

Receiver operating characteristic (ROC) analysis was applied to using SAMG scores to distinguish between participants who scored $<15$ or $\geq 15$ in the FAI (indicating inactive and active participants, respectively). The area under the curve (AUC) was calculated with the $95 \%$ confidence interval (CI), and the optimal cut-off SAMG total score for distinguishing between inactive and active participants was determined. The AUC is a measure of the correct identification of inactive and active participants using the SAMG total score. AUCs range from 0.5 (interpreted as great ambiguity in discrimination) to 1.0 (perfect discrimination). The Sensitivity (the true positive rate) and the 1-Specificity (the false positive rate) for the cut-off point: the "high-SAMG" with scores more than the optimal cut-off SAMG total score and the "low-SAMG" groups with scores less than the optimal cut-off SAMG total score. Demographic parameters and physical function indices were compared between the groups using Welch's test for interval data (age, numbers of housemates and hobbies, grip strength, gait speed and muscle strength), the Brunner-Munzel test for ordinal data (care level), the chi-squared test for nominal data (sex and falling history), and Fisher's exact test (for hospitalization history). HAD Version 16 [36] was used for the descriptive statistics and Welch's and the Brunner-Munzel tests. R version 3.5.3 and the R project package pROC were used for the chi-squared test and ROC analysis [37]. In all the analyses, a p-value $<0.05$ was considered statistically significant.

\section{Results}

Of the 305 eligible people who belonged to a regional salon group and had joined the health exercise program, 20 were excluded because they were under 
the age of 65 years or they did not complete the questionnaires. The remaining 285 participants were included in the analysis. Of these, 224 (79\%) were women and 61 (21\%) were men; the mean age was $76.8 \pm 6.2$ years. Other demographic parameters and the physical function indices are presented in Table 1.

In the ROC analysis, the AUC was 0.78 (95\% CI: 0.58 - 0.99), suggesting that the SAMG score had a favorable diagnostic validity for distinguishing between inactive and active participants, and the optimal cut-off SAMG total score was 48 (Figure 1 ). The sensitivity was $77.98 \%$ and the 1 -specificity was $75.00 \%$.

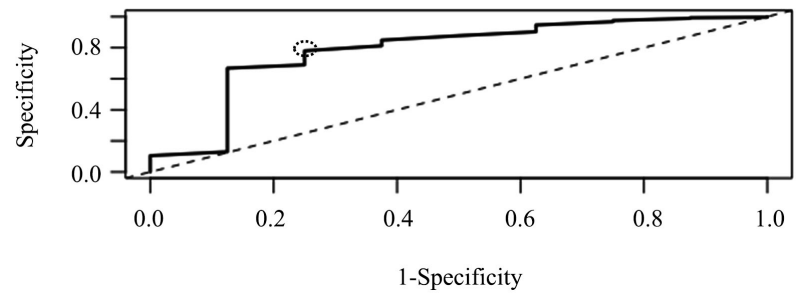

Figure 1. The receiver operating characteristic curve analysis. The cut-off SAMG total score for distinguishing between inactive and active participants (according to the Frenchay Activities Index scores) was 48.49. The area under the curve was 0.78 , the sensitivity (the true positive rate) was $77.98 \%$, and the 1 -specificity (the false positive rate) was $75.00 \%$.

Table 1. Characteristics of the participants $(\mathrm{N}=285)$.

\begin{tabular}{|c|c|c|c|}
\hline & & $\mathrm{n}=285$ & $\%$ \\
\hline \multirow[t]{2}{*}{ Sex } & Men & 61 & $21.40 \%$ \\
\hline & Women & 224 & $78.60 \%$ \\
\hline Age & Mean \pm SD & $76.80 \pm 6.16$ & \\
\hline Housemates & Mean \pm SD & $2.48 \pm 1.35$ & \\
\hline Hobbies & Mean \pm SD & $1.40 \pm 1.06$ & \\
\hline \multirow[t]{2}{*}{ Falling history } & Yes & 29 & $10.18 \%$ \\
\hline & No & 256 & $89.82 \%$ \\
\hline \multirow{2}{*}{ Hospitalization history } & Yes & 12 & $4.21 \%$ \\
\hline & No & 273 & $95.79 \%$ \\
\hline \multirow[t]{7}{*}{ Care level } & Care 3 & 1 & $0.35 \%$ \\
\hline & Care 2 & 1 & $0.35 \%$ \\
\hline & Care 1 & 1 & $0.35 \%$ \\
\hline & Support 2 & 9 & $3.16 \%$ \\
\hline & Support 1 & 18 & $6.32 \%$ \\
\hline & Note & 254 & $89.12 \%$ \\
\hline & Unknown & 1 & $0.35 \%$ \\
\hline Grip strength & Mean \pm SD & $24.47 \pm 7.73$ & \\
\hline Gait speed & Mean \pm SD & $3.08 \pm 1.01$ & \\
\hline Muscle strength & Mean \pm SD & $2.97 \pm 1.04$ & \\
\hline
\end{tabular}

Except where indicated otherwise, the data are presented as numbers and percentages. 
The high-SAMG group included 218 (76\%) of the participants and the low-SAMG group included 67 participants $(24 \%)$. There were statistically significant differences between the groups in sex ratio $(p<0.01)$, the number of housemates $(\mathrm{p}<0.01)$, and the number of hobbies $(\mathrm{p}<0.01)$, but no statistically significant differences in age, falling and hospitalization history, care level, or the physical function indices (Table 2).

\section{Discussion}

The aim of this study was to determine the optimal cut-off point for SAMG, which is an assessment of an individual's intention to achieve their own goals that identified elderly individuals who were inactive with respect to ADLs. In addition, this study compared characteristics, such as demographic parameters and physical function indices, between two groups classified according to the cut-off score (i.e., according to their level of achievement motive).

Table 2. Differences between the high-SAMG and low-SAMG groups.

\begin{tabular}{|c|c|c|c|c|}
\hline & & High SAMG group & Low SAMG group & $\mathrm{p}$ value \\
\hline Sex (Men/Women) & & $39 / 179$ & $22 / 45$ & $<0.01$ \\
\hline Age $($ Mean \pm SD) & & $77.06 \pm 6.21$ & $75.97 \pm 5.98$ & 0.20 \\
\hline Housemates (Mean \pm SD) & & $2.34 \pm 1.31$ & $2.91 \pm 1.40$ & $<0.01$ \\
\hline Hobbies (Mean \pm SD) & & $1.51 \pm 1.09$ & $1.05 \pm 0.88$ & $<0.01$ \\
\hline Falling history (Yes/No) & & $21 / 197$ & $8 / 59$ & 0.59 \\
\hline $\begin{array}{l}\text { Hospitalization history } \\
\text { (Yes/No) }\end{array}$ & & $8 / 210$ & $4 / 63$ & 0.49 \\
\hline \multirow[t]{7}{*}{ Care level } & Care 3 & $1(0.46)$ & None $(0)$ & 0.95 \\
\hline & Care 2 & None $(0)$ & $1(0.46)$ & \\
\hline & Care 1 & $1(0.46)$ & None $(0)$ & \\
\hline & Support 2 & $8(3.67)$ & $1(0.46)$ & \\
\hline & Support 1 & $12(5.50)$ & $6(8.96)$ & \\
\hline & None & $196(89.91)$ & $58(86.57)$ & \\
\hline & Unknown & None $(0)$ & $1(0.46)$ & \\
\hline Grip strength (Mean \pm SD) & & $24.23 \pm 7.45$ & $25.25 \pm 8.61$ & 0.39 \\
\hline Gait speed $($ Mean $\pm S D)$ & & $3.06 \pm 1.08$ & $3.11 \pm 0.74$ & 0.69 \\
\hline $\begin{array}{l}\text { Muscle strength } \\
\text { (Mean } \pm \mathrm{SD})\end{array}$ & & $3.01 \pm 1.03$ & $2.84 \pm 1.07$ & 0.26 \\
\hline
\end{tabular}

Notes: The high-SAMG and low-SAMG groups scored $\geq 49$ and $\leq 48$ in the Scale for Achievement Motive in Geriatrics (SAMG). Except where indicated otherwise, the data are presented as numbers and percentages. $\mathrm{P}$ values were calculated by Welch's test for age, the numbers of housemates and hobbies, grip strength, gait speed, and muscle strength, the Brunner-Munzel test for care level, the chi-squared test for sex ratio and falling history, and Fisher's exact test for hospitalization history. 
In the preventive rehabilitation for the elderly, it is important to make them active, and that this study found that the achievement motivation is related to the active state by examining the relationship between SMAG and FAI. In addition, by determining the cut-off point, it was possible to clarify how much the achievement motive improved and could change to the active state of elderly people. The cut-off point for SAMG of $\leq 48$ could be used as an indicator that an individual was inactive with regard to IADLs. In other words, an assessment from the viewpoint of an individual's drive toward goals could be used to predict that the individual's daily life was likely to be inactive. Furthermore, the cut-off point could potentially be used as a screening test to help understand the conditions of daily life of community-dwelling elderly people in similar populations to the participants of this study. Among those who scored less than the SAMG cut-off point in this study, $75 \%$ were classified as inactive with regard to IADLs according to the FAI. Identifying such individuals in the community could allow them to be subjected to more careful assessment and an evaluation of their need for support for preventive care.

A comparison of the characteristics of the two groups (i.e., low vs. high achievement motive) showed that the group with the lower SAMG scores had significantly more men, more housemates, and fewer hobbies. A previous study using SAMR, which was developed for individuals who received rehabilitation services, also showed that women scored higher than men for achievement motive [38]. With regard to the number of housemates and hobbies, it is indicated that the results of previous studies tend to be similar to this study [21] [39]. These findings showed differences in basic attributes such as sex ratio and the number of housemates between individuals with high motivation and those with low motivation. It is possible that these affect the intention to autonomously perform various IADLs of personal preference, such as hobbies, because women and people with few housemates generally have to perform more domestic chores than men and people with many housemates [17].

On the other hand, there was no difference in level of nursing care, falling history, or hospitalization history. Also, there were no significant differences in the physical function indices characteristics between the two SAMG groups. Major outcomes, such as falling and hospitalization history and the level of nursing care needed, may be a consequence of further deterioration after individuals become inactive with regard to IADLs and there is a decline in physical functions such as muscle strength and gait speed. These inferences suggest that there is a relationship between the cut-off point and classifications of improvement, maintenance, and deterioration, such as major outcomes and physical function, obtained by following the progress longitudinally may be clarified.

\section{Limitations and Future Research Direction}

This study had several limitations. First, it was a cross-sectional study, so no direct causal relationship can be inferred between achievement motive and the state of IADL performance. Second, this research did not allow for random se- 
lection of participants from different areas because it was necessary to recruit participants from the regional salon groups they attended voluntarily and to perform the data collection and measurement during the same period. Third, the participants of this study were many women (Gender ratio is more than 3 times) people aged over 65 years, including several who were certified for nursing care at various levels, so the findings of this study cannot be generalized to all community-dwelling elderly people in Japan. In addition, the study design excluded individuals with a clear decline in cognitive function.

Future longitudinal studies are needed to verify whether individuals predicted to be inactive with regard to IADLs using the cut-off SAMG total score went on to require an increase in the level of nursing care. It is also necessary to verify the effectiveness of early motivation-based interventions for preventive care for individuals predicted to experience a decline in the level of IADLs they perform.

\section{Conclusion}

This study revealed that the achievement motive is related to the state of IADL for the prevention of long-term care of community-dwelling elderly people. The optimal cut-off point of SAMG can be determined to identify whether IADL is active or inactive, and it can be expected to be used as a screening test to predict the IADL status of the subjects. By evaluating an individual's drive toward goals and inferring the state of IADL, it is necessary to consider early intervention for the elderly who can predict a decline in living conditions.

\section{Conflicts of Interest}

The authors declare no conflicts of interest regarding the publication of this paper.

\section{References}

[1] Murray, C.J., Salomon, J.A. and Mathers, C. (2000) A Critical Examination of Summary Measures of Population Health. Bulletin of the World Health Organization 78, 981-994.

[2] Mathers, C.D., Sadana, R., Salomon, J.A., Murray, C.J., Lopez, A.D., et al. (2001) Estimates of Healthy Life Expectancy for 191 Countries in the Year 2000: Methods and Results. Global Programme on Evidence for Health Policy Discussion Paper, 38, $1-55$.

[3] Stucki, G., Bickenbach, J., Gutenbrunner, C. and Melvin, J. (2018) Rehabilitation: The Health Strategy of the 21st Century. Journal of Rehabilitation Medicine, 50, 309-316. https://doi.org/10.2340/16501977-2200

[4] Ministry of Health, Labor and Welfare (2017) Outline of the Revision of the Long-Term Care Insurance System, etc. to Strengthen the Community-Based Integrated Care System in 2017-18.

https://www.mhlw.go.jp/english/policy/care-welfare/care-welfare-elderly/dl/ltcis_20 17_e.pdf

[5] Ministry of Health, Labor and Welfare (2017) Establishing the Community-based Integrated Care System. 
https://www.mhlw.go.jp/english/policy/care-welfare/care-welfare-elderly/dl/establis h_e.pdf

[6] Hikichi, H., Kondo, K., Takeda, T. and Kawachi, I. (2016) Social Interaction and Cognitive Decline: Results of a 7-Year Community Intervention. Alzheimer's \& Dementia: Translational Research \& Clinical Interventions, 3, 23-32. https://doi.org/10.1016/j.trci.2016.11.003

[7] Wen, C.P., Wai, J.P., Tsai, M.K., Yang, Y.C., Cheng, T.Y., et al. (2011) Minimum Amount of Physical Activity for Reduced Mortality and Extended Life Expectancy: A Prospective Cohort Study. The Lancet, 378, 1244-1253. https://doi.org/10.1016/S0140-6736(11)60749-6

[8] Konrath, S., Fuhrel-Forbis, A., Lou, A. and Brown, S. (2012) Motives for Volunteering Are Associated With Mortality Risk in Older Adults. Health Psychology, 31, 87-96.

[9] Kono, A. and Kanagawa, K. (1999) A Qualitative Study on the Structure of “TOJIKOMORI" Phenomenon among Home Disabled Elderly: A Daily Life of House-Bound Elderly. Journal of Japan Academy of Nursing Science, 19, 23-30. (In Japanese)

[10] Cadore, E.L., Pinto, R.S., Bottaro, M. and Izquierdo, M. (2014) Strength and Endurance Training Prescription in Healthy and Frail Elderly. Aging and Disease, 5, 183-195.

[11] Haider, S., Grabovac, I. and Dorner, T.E. (2019) Effects of Physical Activity Interventions in Frail and Prefrail Community-Dwelling People on Frailty Status, Muscle Strength, Physical Performance and Muscle Mass-A Narrative Review. Wiener klinische Wochenschrift, 131, 244-254. https://doi.org/10.1007/s00508-019-1484-7

[12] Wade, D.T., Legh-Smith, J. and Langton Hewer, R. (1985) Social Activities after Stroke: Measurement and Natural History Using the Frenchay Activities Index. International Rehabilitation Medicine, 7, 176-181. https://doi.org/10.3109/03790798509165991

[13] Miller, W.C., Deathe, A.B. and Harris, J. (2004) Measurement Properties of the Frenchay Activities Index among Individuals with a Lower Limb Amputation. Clinical Rehabilitation, 18, 414-422. https://doi.org/10.1191/0269215504cr728oa

[14] Conradsson, D., Ytterberg, C., von Koch, L. and Johansson, S. (2018) Changes in Disability in People with Multiple Sclerosis: A 10-Year Prospective Study. Journal of Neurology, 265, 119-126. https://doi.org/10.1007/s00415-017-8676-8

[15] Hsieh, C.L., Jang, Y., Yu, T.Y., Wang, W.C. and Sheu, C.F. (2007) A Rasch Analysis of the Frenchay Activities Index in Patients with Spinal Cord Injury. Spine, 32, 437-442. https://doi.org/10.1097/01.brs.0000255095.08523.39

[16] Turnbull, J.C., Kersten, P., Habib, M., McLellan, L., Mullee, M.A., et al. (2000) Validation of the Frenchay Activities Index in a General Population Aged 16 Years and Older. Archives of Physical Medicine and Rehabilitation, 81, 1034-1038. https://doi.org/10.1053/apmr.2000.7162

[17] Han, C.W., Yajima, Y., Nakajima, K., Lee, E.J., Meguro, M., et al. (2006) Construct Validity of the Frenchay Activities Index for Community-Dwelling Elderly in Japan. The Tohoku Journal of Experimental Medicine, 210, 99-107.

[18] Han, C.W., Lee, E.J. and Kohzuki, M. (2009) Validity and Reliability of the Frenchay Activities Index for Community-Dwelling Elderly in South Korea. The Tohoku Journal of Experimental Medicine, 217, 163-168. 
[19] Imam, B. and Miller, W.C. (2012) Reliability and Validity of Scores of a Chinese Version of the Frenchay Activities Index. Archives of Physical Medicine and Rehabilitation, 93, 520-526. https://doi.org/10.1016/j.apmr.2011.07.197

[20] Tollén, A., Fredriksson, C. and Kamwendo, K. (2008) Elderly Persons with Disabilities in Sweden: Their Experiences of Everyday Life. Occupational Therapy International, 15, 133-149. https://doi.org/10.1002/oti.254

[21] Sano, N., Kyougoku, M. and Teraoka, M. (2015) Effect of Achievement Motive for Community-Dwelling Elderly Persons on Social Participation and HR-QOL. Sogo Rehabilitaion, 43, 765-772. (In Japanese)

[22] Sano, N. and Kyougoku, M. (2016) An Analysis of Structural Relationship among Achievement Motive on Social Participation, Purpose in Life, and Role Expectations among Community Dwelling Elderly Attending Day Services. PeerJ, 4, e1655. https://doi.org/10.7717/peerj.1655

[23] Tomori, K., Uezu, S., Kinjo, K., Ogahara, K., Nagatani, R., et al. (2012) Utilization of the iPad Application: Aid for Decision-Making in Occupation Choice (ADOC). Occupational Therapy International, 19, 88-97. https://doi.org/10.1002/oti.325

[24] Doig, E., Fleming, J., Cornwell, P.L. and Kuipers, P. (2009) Qualitative Exploration of a Client-Centered, Goal-Directed Approach to Community-Based Occupational Therapy for Adults with Traumatic Brain Injury. The American Journal of Occupational Therapy, 63, 559-568. https://doi.org/10.5014/ajot.63.5.559

[25] Murray, H.A. (1938) Explorations in Personality. Oxford University Press, New York.

[26] Sano, N., Kyougoku, M. and Yabuwaki, K. (2014) Development of a Scale for Achievement Motive in Rehabilitation (SAMR). Sogo Rehabilitation, 42, 667-674. (In Japanese)

[27] Sano, N. (2018) Examination of Validity and Reliability for Prototype Scale to Assess Achievement Motive in Community-Dwelling Healthy Older Adults. Annals of Physical and Rehabilitation Medicine, 61, e426. https://doi.org/10.1016/j.rehab.2018.05.995

[28] Sano, N. (In Press) Examination of Validities and Reliabilities of a Scale for Achievement Motive in Geriatrics (SAMG). Sogo Rehabilitation. (In Japanese)

[29] Singam, A., Ytterberg, C., Tham, K. and von Koch, L. (2015) Participation in Complex and Social Everyday Activities Six Years after Stroke: Predictors for Return to Pre-Stroke Level. PLoS ONE, 10, e0144344. https://doi.org/10.1371/journal.pone.0144344

[30] Lera, L., Albala, C., Leyton, B., Márquez, C., Angel, B., et al. (2018) Reference Values of Hand-Grip Dynamometry and the Relationship between Low Strength and Mortality in Older Chileans. Clinical Interventions in Aging, 13, 317-324. https://doi.org/10.2147/CIA.S152946

[31] Otsuka, T., Domen, K., Liu, M., Sonoda, S., Saitoh, E., et al. (1994) Grip Strength of Healthy Elderly Individuals Method of Measurement and Mean Strength. The Japanese Journal of Rehabilitation Medicine, 31, 731-735. (In Japanese)

[32] van de Port, I.G., Kwakkel, G. and Lindeman, E. (2008) Community Ambulation in Patients with Chronic Stroke: How Is It Related to Gait Speed? Journal of Rehabilitation Medicine, 40, 23-27. https://doi.org/10.2340/16501977-0114

[33] Dean, C.M., Richards, C.L. and Malouin, F. (2001) Walking Speed over 10 Metres Overestimates Locomotor Capacity after Stroke. Clinical Rehabilitation, 15, 415-421. https://doi.org/10.1191/026921501678310216 
[34] Ringsberg, K., Gerdhem, P., Johansson, J. and Obrant, K.J. (1999) Is There a Relationship between Balance, Gait Performance and Muscular Strength in 75-Year-Old Women? Age and Ageing, 28, 289-293. https://doi.org/10.1093/ageing/28.3.289

[35] Katoh, M. and Isozaki, K. (2014) Reliability of Isometric Knee Extension Muscle Strength Measurements of Healthy Elderly Subjects Made with a Hand-Held Dynamometer and a Belt. Journal of Physical Therapy Science, 26, 1855-1859.

[36] Shimizu, H. (2016) An Introduction to the Statistical Free Software HAD: Suggestions to Improve Teaching, Learning and Practice Data Analysis. Journal of Media, Information and Communication, 1, 59-73. (In Japanese)

[37] Robin, X., Turck, N., Hainard, A., Tiberti, N., Lisacek, F., et al. (2019) pROC: Display and Analyze ROC Curves.

https://cran.r-project.org/web/packages/pROC/index.html

[38] Sano, N. and Kyougoku, M. (2015) Examination of Structural Validity of a Scale for Achievement Motive in Rehabilitation (SAMR) for Community-Dwelling Elderly Persons. Sogo Rehabilitation, 43, 341-347. (In Japanese)

[39] Sano, N. and Kyougoku, M. (2017) Examining the Factors Influencing Achievement Motive in Community-Dwelling Elderly People. Progress in Rehabilitation Medicine, 2, Article ID: 20170003. 